\title{
La División Azul
}

\author{
RAMON SALAS
}

\section{LAS RELACIONES HISPANO-GERMÁNICAS ENTRE LA GUERRA CIVIL Y LA SEGUNDA GUERRA MUNDIAL}

Las relaciones entre Alemania y España, siempre buenas desde siglos atrás, nunca fueron fáciles, ni en aún en los tiempos de la Guerra Civil, entre la Alemania nazi y las autoridades nacionales españolas. La causa de sus oscilantes dificultades estuvo en que durante la contienda Franco fue siempre renuente a uncirse al carro de Hitler y de ahí que las relaciones entre ambos presentaran una trayectoria sinuosa en la que los máximos de tensión coincidieron siempre con algún acto del jefe español por el que éste trataba de afirmar su independencia. El momento más delicado fue el de la declaración de la neutralidad de España en caso de conflagración europea con ocasión de la crisis originada por el conflicto de los sudetes en vísperas de Munich ${ }^{1}$. Esta declaración molestó muy particularmente a los alemanes y estuvo dictada por la decidida postura de Franco de evitar cualquier acto que pudiera dar pretexto a la extensión de la guerra que libraba.

Aún así España salió de la contienda ligada a Alemania por una deuda de gratitud; por otra, no despreciable, económica; por su adhesión, el día 27 de marzo de 1939, al pacto Anticomintern y por un tratado de

1 Franco dio conocimiento a Londres el 28 de septiembre de 1938 de su intención de observar una rigurosa neutralidad con la condición de reciprocidad por parte de Francia y Gran Bretaña. DDF Documentos números $98,389,428$, y especialmente, 494, en el que se recoge la noticia de que el Consejo de Ministros de Burgos se ha pronunciado unánimente por la neutralidad. La noticia fue recibida por profundo desagrado en Berlín y Roma. 
amistad signado el día 31 de marzo del mismo año, pero ninguno de esos lazos obligaba a España a apartarse de la tradición política de neutralidad que Franco rearfirmó en sus entrevistas de 10 y 15 de marzo con el general Gámbara ${ }^{2}$. Alemania obtenía de España, a pesar de su contribución a la victoria de Franco, mucho menos que de las naciones centro europeas a las que iba captando, de grado o por fuerza, a su política prebélica.

En el orden económico se abrieron negociaciones para saldar la deuda de guerra española, tema objeto de prolongadas conversaciones que incluía no sólo el establecer el monto total de la obligación contraída sino también la forma de efectuar el pago y el intercambio de mercancías que habría de producirse en lo sucesivo. El día 28 de febrero de 1941, el Gobierno español dio su conformidad a facturas y cuentas alemanas por un importe total de $371.819 .548,46 \mathrm{RM}^{3}$.

Antes, el 22 de diciembre de 1939, había firmado un acuerdo de relaciones económicas con Alemania, a las que se daba trato preferencial, y, poco, despues, con Francia e Inglaterra, naciones con las que llegó a sendos convenios comerciales en enero y marzo de 1940.

Estos últimos suscitaron el recelo de los alemanes que entendieron que España había violado lo pactado en el tratado de amistad y en el protocolo comercial germano-español lo que aumentó el decontento de Hitler por la conducta de Franco. Esto ocurría después de iniciada la II Guerra Mundial, pero ya con anterioridad, el día 26 de abril de 1939, pocos después de que finalizara la nuestra, se habían reunido en Roma, Mussolini, Goering y Ciano y, según dicen los editores de los documentos secretos alemanes, trataron de asegurarse el uso, en caso de guerra, de bases navales $y$ aéreas en las Islas Baleares y en territorio penínsular español lo que de ser cierto hubiera supuesto una nueva decepción de las potencias fascistas pues el hecho histórico es que España no las

${ }^{2}$ Los archivos secretos de la Wilhelmstrasse capítulo VII, documentos 525 y 550 . Gambara, general Jefe del CTV, dejaba este puesto para ocupar él de embajador de Italia en Madrid, ciudad que caería pocos dias después de sus entrevistas con Franco.

${ }^{3}$ Política Comercial Exterior en España (1931-1975), obra colectiva dirigida por Angel Viñas Martín, tomo I, pág. 231. 
cedió, ni aún a título de usufructo eventual, ni en las fases en que fue más acusada su asociación con ellas ${ }^{4}$.

En aquel momento el deseo de Goering fue el de regresar a su país haciendo escala en España, donde le hubiera gustado asistir a la parada conmemorativa de la victoria que celebraron las Fuerzas aéreas en el Aeropuerto de Barajas, pero Franco puso objecciones a su solicitud y entonces el mariscal alemán propuso que el encuentro se efectuara a bordo del vapor en que viajaba.

La contrapuesta de Franco fue la de recibirle en suelo español y al mantenerse inflexibles las respectivas posiciones se canceló la entrevista con notable disgusto de Goering que en adelante no disimularía su antipatía hacia Franco ${ }^{5}$.

Por si fuera poco, Serrano Súñer, se olvidó - voluntaria o involuntariamente - de alabar la contribución alemana a la victoria de Franco en su discurso de contestación a Mussolinni en la cena de gala que se ofreció en el Palacio de Venecia en honor de la misión española que había acompañado a Italia a los compatientes del CTV. El ministro español, que se mostró extremadamente hóstil hacia Gran Bretaña y Francia, no citó ni una sola vez a los alemanes que habían combatido en España. El embajador Mackensen comentaba en su informe «que ello era tanto más sorprendente cuanto que Serrano Súner había dado una visión retrospectiva de los acontecimientos producidos durante los dos años y medio sin decir una sola palabra de esta contribución, que es nuestra, y a la que debe poder festejar hoy la victoria" ${ }^{6}$.

${ }^{4}$ Se habló mucho de la utilización de los aeródromos situados a orillas del Mar Menor como punto de apoyo y suministro para el bombardeo de Gibraltar por aviones italianos en junio de 1940. Y efectivamente tomaron tierra en El Carmolí dos grupos de bombarderos Savoia 79 en los últimos días de aquel mes, viajando con ellos nada menos que Etore Muti, secretario general del Partido Fascista, pero no encontraron la ayuda que esperaban y necesitaban - bombas y combustibles - y tuvieron que regresar a su país.

${ }^{5}$ Todas las negociaciones que tuvieron por objeto convenir una entrevista entre Franco y Goering se encuentran muy bien documentadas en ASW Capítulo VIII, en el que se reúnen 29 documentos de los que 13 giran en tono a los preparativos del frustrado viaje del mariscal alemán a España.

${ }^{6}$ El Decreto, publicado en el Boletín Oficial del Estado, 248 del martes 5 de septiembre de 1939, decía: "Constando oficialmente el estado de guerra que por desgracia existe entre Inglaterra, Francia y Polonia, de un lado y Alemania de otro, Ordeno por el presente Decreto, la más estricta neutralidad a los súbditos españoles con arreglo a las leyes vigentes y a los principios del Derecho Público Internacional». 
Todos estos incidentes iban poniendo una cierta acritud en unas relaciones que, sin embargo, se mantuvieron buenas, aun después de la firma del pacto germano-soviético que dejó estupefactas a las gentes de España sin distinción de ideas pues la sorpresa no fue menor entre los vencidos que entre los vencedores.

Para éstos la alianza entre Hitler y Stalin no estaba muy de acuerdo con el espiritu del pacto Anticomintern y el recelo mutuo se acrecentó facilitando la inicial postura neutralista de Franco al estallar la guerra que fue reiterada, solamente el día 4 de septiembre, al tiempo que exhortaba a las potencias a resolver sus diferencias pacíficamente.

\section{DE LA NEUTRALIDAD A LA NO BELIGERANCIA, ESPAÑA AL BORDE DE LA GUERRA}

La guerra se mantuvo, de momento, alejada de España y en un tono menor lo que permitió mantener la neutralidad sin excesivas dificultades.

España, rodeada totalmente por naciones enemigas de Alemania, permaneció al margen del conflicto atendiendo más a sus intereses que a la gratitud que la unia a Alemania o a la hostilidad que sentía hacia Francia y Gran Bretaña. Fue en esta situación en la que firmó los acuerdos comerciales a que nos hemos referido anteriormente y que no tenían otro objetivo que el de garantizar el mínimo de suministros que precisaba la nación para que pudieran subsistir sus habitantes, en gravísimas dificultades, por las devastaciones originadas por la guerra y por las crecientes dificultades que oponían los aliados, y los propios Estados Unidos, al comercio exterior de España.

El único temor español eral el de que los aliados intentaran por la fuerza ocupar su territorio, o parte de él, y efectivamente, los británicos tuvieron dispuesto un plan para apoderarse de las Islas Canarias aun a costa de que tal hecho entrañase la guerra con España ${ }^{7}$.

7 A. Marquina Barrio, España en la política de seguridad occidental 1936-1986. Ed. Ejército, Madrid 1986, págs. 48-58. 
La situación cambió radicalmente a partir del día 10 de mayo de 1940, fecha en la que los alemanes lanzaron sus ejércitos contra Holanda, Bélgica y Francia arrollando a sus Fuerzas Armadas. En muy pocas semanas España se encontró fronteriza de Alemania y Franco, temiendo la extensión del conflicto a su costa, inició una política de halagos y dilaciones que alcanzó momentos especialmente drámaticos a partir de la entrada de Italia en la guerra.

Hasta entonces Franco había distribuido de forma más o menos ponderada, sus solicitudes entre Alemania y las potencias occidentales pero el cambio radical de la situación estratégica imponia una profunda modificación de la actitud española, en forma paralela a como reaccionaron los restantes países europeos que aún permanecían neutrales. El día 12 de junio de 1940 el Gobierno de Madrid, a petición de Mussolini, cambió su postura neutralista por otra de «no beligerancia» que Franco explicó de la siguiente manera: "Ahora las nubes de la guerra han llegado mucho más cerca. Hay muertos italianos en los campos españoles y la simpatía de España por Italia es muy grande; en una palabra, la expresión de no beligerancia puede interpretarse como señal de simpatía más definida por Italia y de una actitud muy atenta» ${ }^{8}$.

La victoria alemana había puesto en la frontera española a diez de sus mejores divisiones y todo permitía suponer que no se detendrían en ella y continuarían a través de la Península Ibérica hacia Gibraltar y el norte de Marruecos, por lo menos esa era la opinión del diplomático norteamericano Robert Murphi ${ }^{9}$. Mientras Hitler confió en que la derrota de Francia sería suficiente para que Gran Bretaña aceptara un acuerdo que pusiera fin a la guerra, la situación española fue tolerable, pero cuando Churchill aclaró la irreductible postura británica de llegar hasta el fin, las cosas se pusieron difíciles para Franco. Éste había enviado el día 3 de junio un mensaje personal a Hitler, del que fue portavoz el general Vigón, Jefe del Alto Estado Mayor, quien lo entregó personalmente el día 16, en el que felicitaba efusivamente a los alemanes por su triunfo, en términos semejantes a los que por aquellas fechas recibió de casi todos los Estados europeos incluida la Unión Soviética ${ }^{10}$.

${ }^{8}$ Boletín Oficial del Estado, número 164 de 12-6-1940.

${ }^{9}$ R. Murphy, Diplomat Amomg Warriors, pág. 103.

10 Italia declaró la guerra a Francia y Gran Bretaña el lunes 10 de junio con efectos a partir del día 11. Ese mismo día el general Gámbara abandonó su puesto en Madrid para tomar el mando de un Cuerpo de Ejército. El sábado 15 una nota del Gobierno español daba cuenta de que fuerzas jalifianas habían ocupado Tánger «con objeto de garantizar la 
Tres días más tarde, el 19 de junio, Franco daba un paso más y presentaba a Alemania un memorándum en el que se mostraba dispuesto a entrar en la guerra del lado alemán si se cumplía una serie de condiciones que hicieran posible su participación, que se decía desear, y que Alemania no parecia dispuesta a otorgar.

Políticos, estrategas y diplomáticos, coincidían en que a los británicos solo se les podía vencer atacándoles en las rutas de su imperio. Los almirantes alemanes propugnaban la ocupación de bases desde las que se pudiera hostilizar y aún cortar las rutas inglesas y apuntaban específicamente además de a Gibraltar a las Azores y Canarias, coincidiendo en esto con los británicos que querían esos mismos puntos de apoyo aunque su posición en aquel momento no les permitiera intentar una operación que tuvieron planteada para ser realizada en septiembre 1941 según declara Churchill en sus memorias ${ }^{11}$.

Sólo España podia proporcionar esas bases y Franco se vio sometido a una casi insorportable presión que aguantó con una resistencia pasiva sumamente hábil. Opuso a los violentos políticos nazis, no una pared, sino un colchón y contra él perdieron intensidad y vigor sus esfuerzos.

Para esta nueva política Franco modificó la composición de su Gobierno en el que el coronel Beigbeder, que había presidido la fase desagradable pero relativamente suave de apaciguamiento a los occidentales, para conseguir incrementar el comercio con ellos y asegurar el abastecimiento de la población, fue sustituido por Serrano Súñer. Éste hasta entonces ministro del Interior, era grato a los alemanes, a pesar del incidente del Palacio de Venecia, y a él tocaría la ingrata tarea de calmar a los alemanes con una política en la que muchas veces, fue en su germanofilia, más allá de lo que aconsejaba la prudencia ${ }^{12}$.

El momento estelar de este nuevo rumbo de la política exterior de España fue la reunión de Franco con Hitler en Hendaya y la firma el día 23

neutralidad de la zona" y el general Vigón, Jefe del Alto Estado Mayor, viajaba al Cuartel general de Hitler donde fue recibido por éste el domingo 16 de junio. En esos dias la Unión Soviética envió sendos ultimátums a Letonia y Estonia y en Lituania se constituía un Gobierno grato a la URSS.

11 Operación «Pilgrim», posterior a los planes Sapphic y Puma. CHURCHILL, Thier Finest Hour, pág. 443.

${ }_{12}$ Serrano Súñer fue nombrado ministro de Asuntos Exteriores el 16 de octubre de 1940. El incidente lo relata el autor en su libro Entre España y Gibraltar, y es objeto también del documento 565 del capítulo VII de ASW. Serrano Súñer, en su discurso de respuesta a Mussolini en la cena de gala que ofreció en honor de la misión española que había acom- 
de octubre de 1940 del protocolo secreto tripartito por el que España se comprometía a entrar en la guerra, "una vez satisfechas sus demandas» ${ }^{13}$.

Consecuencia inmediata de este protocolo fue la Instrucción Félix que tenía por objeto «arrojar a los ingleses del Mediterráneo occidental» previa ocupación de Gibraltar. La Instrucción llevaba fecha 12 de noviembre y la operación se preveía para 10 de enero de 1941 pero Franco consiguió demorar la decisión después de sendos viajes de Serrano Súñer a Alemania y del almirante Canaris a España. Se sucedieron situaciones tensas y enervantes y, finalmente, Hitler desistió el día 10 de diciembre «pues ya no existen los requisitos políticos necesarios". España había conseguido mantenerse apartada de la guerra aun a costa de disgustar profundamente a Hitler y Mussolini, a los que tanto debía ${ }^{14}$.

¿Cuál fue la razón del cambio de actitud del Jefe del Estado Español a lo largo del 1941? Indudablemente él, y su consejero Serrano Súner, creyeron firmemente en la victoria alemana después de su arrolladora ofensiva de mayo de 1940 y ese convencimiento les llevó a la política de "no beligerancia" e incluso a su no disimulado deseo de buscar posiciones ventajosas en el nuevo orden mundial, o por lo menos europeo, que parecía a punto de establecerse y de ahí sus ofrecimientos a Hitler. La resistencia de éste a acceder a las pretensiones españolas y el persistente consejo por parte de algunas personalidades militares muy especialmente marinos y entre ellos, de forma destacada, el capitán de navío D. Alvaro Espinosa de los Monteros, -que desde su puesto de agregado naval en Roma insistía reiteradamente en señalar los peligros de uncirse al bando de los aparentemente vencedores pero que, en su opinión, terminarían siendo vencidos-, acabaron por introducir la duda en el ánimo de Franco y como consecuencia una moderación en sus relaciones con

pañado a los combatientes del CTV, no dijo una sola palabra en elogio de los alemanes que habían combatido en España y uello es tanto más sorprendente cuanto que Serrano Súner había hecho una visión retrospectiva de los acontecimientos producidos durante los últimos dos años y medio sin que dijera una sola palabra de esta contribución, que es nuestra, y a la que debe poder festejar hoy la victoria" (la frase entrecomillada es de! embajador alemán en Roma von Mackensen).

${ }_{13}$ Copias del protocolo, en español y en la traducción inglesa del Departamento de Estado Norteamericano, figuran en el libro de Ramón Serrano Súñer: Entre el silencio y la propaganda, la historia como fue, págs. 312 y 313.

${ }_{14}$ Hitier dijo al embajador italiano Alfieri: «ltalia y Alemania podian haber esperado más gratitud de Franco después de lo que habian hecho por él, que en última instancia, les debia su existencia política. Habría que recordar esa actitud». Documentos diplomáticos Alemanes, documento número 538, en el que figura el acta de la reunión entre ambos políticos en la cancilleria berlinesa el 19 de diciembre de 1940. Citado por R. Proctor: Agonía de un neutral, pág. 112. 
Alemania a la que en adelante daría siempre largas para evitar verse comprometido en una guerra cuyo final ya no se le aparecía tan evidente aunque aún tardará bastante en perder su fe en el triunfo alemán ${ }^{15}$.

Diez días después de que Hitler cancelara la operación «Félix" su EM ponía en marcha el plan «Barbarroja» con el que el punto de aplicación del esfuerzo de guerra alemán se orientaba decididamente hacia el Este con el objetivo "de aplastar a la Rusia Soviética mediante un rápida campaña».

Sin embargo antes de que los hasta entonces victoriosos ejércitos alemanes se pusieran en marcha hacia Moscú tenían que resolver el problema de la seguridad de su flanco derecho en el que Italia había fracasado ruidosamente en su intento de establecer su hegemonía en la península Balcánica. Una nueva campaña, previa a «Barbarroja», llevaría a los alemanes a la ocupación de Bulgaria, Yugoslavia y Grecia, incluidas las islas de los mares Jónico y Egeo y la de Creta y traería de nuevo a España al primer plano de las consideraciones estratégicas. Tanto Hitler como Mussolini insistieron en que España entrara en la guerra. Sus quejas ante las vacilaciones de Franco eran constantes y la presión ejercida pertinaz y poderosa. Fueron los momentos quizás más peligrosos para España y sus relaciones con Alemania alcanzaron extremos de gran tirantez. La operación «Félix» volvería a plantearse y el Gobierno español recibió auténticos ultimatum. Ribbentrop recordó a Franco que «sin la ayuua de Hitler y de Mussolini, hoy no habría ni España nacional ni Caudillo" y agregó que "a menos que el Caudillo decida inmediatamente unirse a la guerra de las potencias del Eje, el Gobierno de Alemania no puede sino prever el fin de la España nacional ${ }^{16}$ ".

La clara amenaza alemana fue seguida de una cierta distensión y poco después, el propio Hitler escribió el 6 de febrero una carta a Franco a la que siguió una reunión seis días más tarde entre Franco y Mussolini celebrada en Bordighera.

La carta de Hitler no fue contestada por Franco hasta el día 26, después de su entrevista con Mussolini, y el gobernante español la en-

15 "Apelación al tribunal de la Historia sobre Hendaya". documento inédito redactado por Hernando, Juan, Gonzalo e Ignacio Espinosa de los Monteros y Bermejillo en octubre de 1979 y que Ignacio tuvo la atención de enviarme el 12 de noviembre de 1979.

${ }^{16}$ Documentos diplomáticos alemanes. Doc. 682. Mensaje de Ribbentrop a Stohrer, de 21 de enero de 1941. Citado por R. Procto: op. cit., págs. 116-117. 
cabezaba asi: «Querido Hitler: Su carta de 6 de febrero hace que le responda de inmediato». La gallegada debió irritar al dictador alemán que comentó: «Estos últimos meses han demostrado que Franco no es un buen camarada" y en conversación con Ciano añadió que le había irritado muy particularmente el que Franco sostuviera que sin la ayuda germano-italiana también hubiera ganado la guerra civil, aunque aceptaba que hubiera tardado algo más en lograrlo ${ }^{17}$.

En ese momento tanto los alemanes como los italianos jugaron fuertemente la carta de la deuda española de guerra, cuyo monto exageraron deliberadamente, pero Franco, se mantuvo en su postura e Hitler terminó dejándolo por imposible ${ }^{18}$.

Resuelto el problema de su flanco sur, el mando alemán temió que Gran Bretaña aprovechara la ocasión para actuar en occidente y para preveer ese peligro preparó el plan "Isabel» que sólo se desencandenaría en la eventualidad de una acción británica o norteamericana, -en el caso de que los Estados Unidos se decidieran a entrar en la guerrasobre el territorio peninsular o insular de España. Si se produjera, los alemanes ocuparian la Península Ibérica. La instrucción «Isabel» llevaba fecha 7 de mayo y supuso la última intimidación importante de los alemanes para arrastrar a España a la guerra ${ }^{19}$.

\section{LA INVASIÓN DE LA URSS: FORMACIÓN DE LA DIVISIÓN AZUL Y LA ESCUADRILLA DE VOLUNTARIOS}

Un mes más tarde, el 22 de junio de 1941, las tropas alemanas rebasaban las líneas de demarcación que establecieron sobre suelo poglaco en septiembre de 1939 e iniciaron su impetuoso avance hacia el interior de la Unión Soviética por el territorio que ésta arrebató entonces al desaparecido Estado centro-europeo. En España la noticia de este acontecimiento, totalmente inesperada, produjo un efecto igual y contrario al que dos años antes causara el pacto germano-soviético. Las relacio-

17 DDA. Doc. 117; acta de la reunión de Hitler y Ciano de 2 de marzo de 1941. Citado por PROCTOR op. cit., págs. 123.

${ }_{18}$ Política Comercial exterior en España 1931/1975. A. VIÑAs y equipo. Tomo I, págs. 223-235

19 R. Proctor op. cit. pág. 125. 
nes germano-españolas, difíciles en ese momento, mejoraron de forma notable e inmediata. La reacción oficial y popular fue entusiasta y aquel mismo día Serrano Súñer, ministro de Asuntos Exteriores y Presidente de la Junta Política, después de despachar con Franco, ofreció al Embajador alemán, von Stohrer, la cooperación española en la guerra que se iniciaba, aunque aclaró que «esta manifestación de solidaridad se hace, por supuesto, independientemente de la completa entrada de España en la guerra al lado del Eje ${ }^{20}$ \%. Hitler aceptó rapidamente la oferta y el día siguiente de recibirla su ministro de Asuntos Exteriores dirigía a su embajador en Madrid el siguiente cablegrama: "De acuerdo, pero dígales que se den prisa». $Y$ efectivamente se la dieron ${ }^{21}$.

Los falangistas se lanzaron a las calles en demostraciones jubilosas que reclamaban la presencia de España en la que ya comenzaba a denominarse "Cruzada Anticomunista», y en Madrid una manifestación multitudinaria se congregó en la mañana del martes 24 de junio ante la sede de la Secretaria General del Movimiento reclamando la inmediata apertura del reclutamiento de voluntarios. Serrano Súñer, dirigiéndose a las masas enfervorizadas, dijo que era hora de saldar «la deuda de sangre» contraída con Alemania y acusó a Rusia con las siguientes palabras: "Camaradas: no es hora de discursos pero sí de que la Falange dicte en estos momentos la sentencia condenatoria. ¡Rusia es culpable! Culpable de nuestra guerra civil; culpable de la muerte de José Antonio, nuestro fundador, y de la muerte de tantos soldados caídos en aquella guerra por agresión del comunismo ruso. El exterminio de Rusia es exigencia de la historia y del porvenir de Europa».

A pesar de estas duras expresiones la intención de Franco se reducía a dejar constancia de la adhesión de España a la acción alemana, con una contribución importante pero limitada. Ésta se concretó en los días inmediatamente siguientes en una división de Infanteria de línea y una Escuadrilla de aviones de combate, que la proporcionaría apoyo aéreo. Según Demetrio Carceller, entonces ministro de Industria, se trataba de "un gesto sencillo para satisfacer al Eje» y añadía que «si Franco hubiese actuado de otra manera se habría equivocado totalmente ${ }^{22}$ ». Pero la opinión del ministro, mezcla paradójica y sorprenderite de falangista y anglófilo, no es del todo

${ }^{20}$ R. PROCTOR op. cit. pág. 132.

${ }_{21}$ G. R. KleinfELd y L. A. TAmbS, La División española de Hitler. Editorial San Martín, 1983, pág. 18.

${ }^{22}$ US Papers, 1941, págs. 911-913. Citado por Proctor pág. 143. 
válida. Entre los jóvenes que habian hecho la guerra o que queriéndola hacer se vieron imposibilitados de lograr su propósito por haber permanecido durante toda ella en territorio republicano, el deseo de participar en ésta, que contemplaban como continuación de aquélla, fue espontáneo, sincero y entusiasta, y ningún Gobierno hubiera podido sustraerse a esa realidad que coincidía con la pretensión alemana de que todos los Estados europeos contribuyeran en una empresa que su propaganda se señalaba como quehacer colectivo de Europa. De hecho, Hungría, Eslovaquia, Rumanía e Italia declararon la guerra a la Unión Soviética, y noruegos, daneses, filandeses, holandeses, flamencos, suecos, croatas y portugueses, enviaron combatientes voluntarios a los que se unirían la División y la Escuadrilla españolas.

A partir de entonces Franco mantendría la teoría de que esta nueva campaña era una guerra aparte y distinta de la que se libraba en Occidente y en la que observaría una neutralidad exquisita. Los aliados, que no entendian de sutilezas, consideraron la postura española como una grave vulneración de su neutralidad, aun a pesar de que no eran los españoles los únicos neutrales que contribuían o contribuirían con voluntarios a una lucha que iba teniendo un carácter cada vez más universal. Muchos norteamericanos combatían al lado de los británicos contra los alemanes y de China contra Japón; hubo suecos en la filas finlandesas y muchos republicanos españoles formaban en las francesas y británicas, pero el gesto de Franco, si bien sirvió para mejorar su posición frente a Alemania, contribuyó a empeorar aún más sus tensas relaciones con los aliados, que protestaron la decisión española.

Serrano Súñer hubiera deseado que la Embajada española hubiera estado constituida por falangistas y organizada y encuadrada por el Movimiento Nacional, pero el Gobierno, presionado por el Ejército, decidió que fuera una unidad militar aunque de la recluta se encargara inicialmente el General Moscardó, Jefe Nacional de Milicias. Actuaron como Centros de reclutamiento las Delegaciones Provinciales de FET pero muy pronto el Ministerio del Ejército se hizo cargo de todo y una Orden General del Estado Mayor Central fechada el 28 de junio especificaba que los Capitanes Generales reclutarian y encuadrarían a los voluntarios de los que más del 50 por 100 debían proceder de las filas militares. Se designó para el mando de la División al General don Agustín Muñoz Grandes, Jefe de la 22 División y Gobernador Militar del Campo de Gibraltar, y en esa misma fecha, el EM del Aire dispuso la constitución de una Escuadrilla, igualmente de voluntarios, de la que se nombró Jefe al Comandante don Angel Salas Larrazábal. 
La elección de estos hombres daba clara idea de la importancia que en los medios castrenses se daba a la contribución española "en la lucha contra el comunismo". El General Muñoz Grandes era uno de los más prestigiosos del Ejército español en cuyas filas habia destacado de forma muy notable. En África al frente de la «Harka« que llevó su nombre; durante la República como creador de los guardias de asalto y en la guerra civil, que le sorprendió en Madrid, donde el Gobierno hizo notables esfuerzos para que sirviera en sus filas, al mando sucesivamente de la segunda brigada de Navarra, la 61 división y el Cuerpo de Ejército de Urgel. Al terminar la contienda fue ministro Secretario General del Movimiento y siempre hombre de la máxima confianza de Franco. El Comandante Salas había sido uno de los "ases" de la caza, distinguiéndose al frente de una escuadrilla de He.-51, como segundo jefe del grupo Morato y al mando de éste desde septiembre de 1937 al final de la guerra ${ }^{23}$.

Los voluntarios afluyeron en número muy superior al requerido y finalmente fueron selecionados 641 oficiales, 2.272 suboficiales y 15.780 soldados, para nutrir la división y 28 oficiales y suboficiales - de ellos 17 pilotos- y 81 cabos y soldados para la escuadrilla. En total 18.801 hombres.

A la división se la dio provisionalmente una estructura cuaternaria similar a las que actuaron durante la guerra civil. Los regimientos de infantería fueron organizados por sus respectivos jefes, los coroneles Rodrigo, Pimentel, Vierna y Martínez Esparza, todos ellos de brillante historial al mando de tropas de choque, y el de artillería por el coronel Badillo.

El regimiento Rodrigo se constituyó en Madrid con muchachos de la capital y de las regiones militares de Zaragoza y Burgos. El regimiento Esparza en Sevilla con mozos andaluces y de la zona española de Marruecos. El regimiento Vierna en Valencia con gentes levantinas y catalanas y el regimiento Pimentel en Valladolid con hombres de Castilla, León y Gali-

${ }^{23}$ Muñoz Grandes fue ascendido a Teniente General a su regreso a España y ocupó entre otros puestos el de ministro de! Ejército desde el 19 de junio de 1951 al 25 de febrero de 1957; el de vicepresidente del Gobierno desde el 10 de julio de 1962 al 22 de julio de 1967; ascendió a Capitán General al cesar en Ministerio del Ejército y simultaneó la vicepresidencia del Gobierno con la Jefatura del AEM, siguiendo en aquel cargo al dejar éste último. Murió el 11 de julio de 1970. El Comandante Salas después de mandar la Escuadrilla, ascendió a Teniente Coronel, fue agregado Aéreo a las embajadas de España en Alemania, Suiza, Portugal y Francia, alcanzó el empleo de Teniente General, era miembro del Consejo de Regencia al morir Franco y fue Senador de designación real en las Cortes Constituyentes. 
cia. Voluntarios procedentes de toda España se dieron cita en la división predominando jóvenes de ideología falangista o tradicionalista, que por su edad o por haber permanecido en territorio republicano, no habían tenido oportunidad de participar en la guerra de España, aunque no faltaran los veteranos de ésta. Su origen era muy heterogéneo mezclandose en sus filas obreros, campesinos y estudiantes con una fuerte proporción de éstos últimos. La oficialidad era profesional en sus escalones altos y provisional, veteranos de guerra la casi totalidad de los suboficiales y oficiales subalternos. El conjunto, totalmente improvisado, carecia de la cohesión, la instrucción y el adiestramiento, que hacen de una muchedumbre un instrumento militar apto para la guerra. Lo que faltaba de capacidad era suplido por entusiasmo pero se hacía notar la falta de calidad y la impresión general era de que se había reunido una "harka" de milicianos irregulares y no de una tropa organizada. Por añadidura carecian de armamento y material. Como en nuestra guerra, predominaba el aire montaraz y guerrillero sobre la disciplina y la estructura de un auténtico cuerpo táctico.

En aviación, donde la totalidad de la escuadrilla se extrajo de las unidades aéreas, la situación era mejor aunque también se trataba de un conjunto improvisado y sin referencia a ninguna organización previa.

Para transformar a esa masa de combatientes, congregada precipitadamente, en una unidad militar eficiente salió para Alemania una comisión española que trató con el General Fromn, jefe del ejército alemán de reserva, los términos en que habría de establecerse su dotación e instrucción. Se acordó que los gastos que originaran los voluntarios españoles correrian a cargo de Alemania, que también atendería a su uniformidad y manutención. La División adoptaría la organización alemana ternaria y el exceso de personal sería dado de baja. Los que permanecieran recibirian sus haberes, a partir del día que atravesaran los Pirineos, al igual que el resto de los miembros del ejército alemán de los que no se distinguirian más que por un escudo que lucirían en el brazo izquierdo con la bandera española remontada por la palabra España ${ }^{24}$.

Resueltos todos estos problemas, los voluntarios iniciaron su marcha hacia Alemania el 13 de julio siendo despedida la primera expedición, que partió de Madrid, en medio de un entusiasmo delirante. El 23 salió el grupo final de la División y al día siguiente los miembros de la escua-

24 Kleinfeld y Tambs, op. cit., págs 41-45. 
drilla expedicionaria. Aquéllos con destino a Grafenwörhr en Baviera y éstos al aerodromo de Verneuhen, en las proximidades de Berlín, donde recibirían vestuario, armamento, pertrechos, material de vuelo, instrucción y adiestramiento.

En el intervalo se celebró en España el $V$ aniversario del alzamiento militar y en su conmemoración Franco pronunció un belicioso discurso que fue recibido con gran complacencia en los medios alemanes y con singular alarma en las embajadas de los países occidentales a los que el Jefe del Estado español culpó, no sin razón, de las dificultades alimenticias por las que atravesaba el país y de uponernos obstáculos políticos incompatibles con nuestra soberanía y nuestra dignidad de nación libre ${ }^{25}$ ».

La División española pasó a ser la 250 del ejército alemán pero siempre fue conocida como "División Azul» o «Blau Division". Al integrarse en él perdió su organización provisional española y de acuerdo con las «Tablas de Organización y Equipo" de la Whermacht se constituyó bajo el modelo germánico quedando sus regimientos limitados a tres, aunque, para reducir las repatriaciones, que hubieran sido impopulares, se crearon un batallón de depósito y sendos grupos regimentales de anti-tanques y exploración que engrosaron a las tropas de apoyo, las formadas por un regimiento de artillería de cuatro grupos, un batallón de zapadores, un grupo de transmisiones y los servicios divisionarios de Intendencia, Sanidad, Transportes, Veterianaria, Correos y Orden y Policía.

Los regimientos de infantería recibieron los número 262, 263 y 269 y las restantes unidades el mismo que la División cuyos efectivos finales quedaron establecidos en 17.909 hombres equipados con material y armas alemanas y dotados para su movilidad con 5.610 caballos requisados en los Balcanes y «a no dudar, inferiores a lo admisible ${ }^{26}$ ».

El Coronel Rodrigo, el de mayor antigüedad, pasó a ocupar el puesto de segundo Jefe de la División y comandante de la infantería divisionaria, quedando Pimentel al mando del regimiento 262, Vierna del 263 y Martínez Esparza del 269. Badillo permaneció como comandante de la artillería y jefe del regimiento del Arma.

\footnotetext{
${ }^{25}$ Mundo, año II, N. ${ }^{\circ} 67$ de 17 de agosto de 1941, págs. 638-639.

26 Kleinfeld y TamBS, op. cit., pág. 71.
} 
El día 31 de julio los componentes de la División y el 16 de agosto los de la Escuadrilla, juraron fidelidad al "Comandante Supremo del Ejército alemán, Adolfo Hitler, en la batalla contra el comunismo", con una fórmula redactada especialmente para el caso y que difería de la que se exigía a los soldados alemanes, limitando su alcance a una finalidad específica: la lucha contra el comunismo.

\section{LA LARGA MARCHA HACIA EL FRENTE}

Después de unas apresuradas jornadas dedicadas a la instrucción intensiva en el manejo de las armas y equipos que habian recibido los voluntarios de la División iniciaron su marcha hacia el frente de combate con apenas un barniz de instrucción y adiestramiento. Los alemanes del destacamento de enlace, y muy especialmente su jefe, el Comandante von Oertzen, se quejaban constantemente de la mala presentación, la escasa disciplina, la poca marcialidad y el nulo interés que presentaban por adquirir todas esas virtudes, pero los españoles, con sus peculiaridades buenas y malas al hombro, marchaban impacientes a la guerra.

Se les había dicho que sobre ellos recaería el honor de entrar junto a sus camaradas alemanes en Moscú y eran tantos y tan espectaculares los éxitos que lograban cada día los tres Grupos de ejércitos que habían invadido la Unión Soviética que temían no llegar a tiempo para participar en tan magno acontecimiento y de ahí que recibieran con gran alegría la orden de embarcar hacia el frente. La División constituía entonces un abigarrado conjunto que a sus casi 6.000 caballos unía 965 vehículos, 48 cañones de 105 y una copiosa impedimenta que dificultaba los movimientos y exigía para su transporte un orden y una organización que la División estaba bastante lejos de alcanzar. Por añadidura «la inexperiencia de los españoles" se combinaba con la lamentable condición de los caballos servios, lo que contribuía a aumentar la confusión en las columnas de abastecimiento.

Su aproximación al frente, que se inició los primeros días de septiembre, se efectuó en tres etapas bien diferenciadas. Durante la primera el grueso de la División se trasladó en ferrocarril hasta Suwalky, ciudad polaca situada próxima a la frontera con la Prusia Oriental y dentro del territorio que después del reparto de Polonia se había adjudicado a la Unión Soviética en septiembre de 1939. Allí se concentraron en la zona 
Grodno-Reuss-Treuburg, antes de dirigirse a Smolensko donde debía incorporarse al Grupo de Ejércitos Centro, que mandaba el Mariscal von Bock, y tenía como objetivo Moscú. Su destino concreto era el Noveno Ejército del General Adolf Strauss, pero el 6 de septiembre se ordenó que la 250 División pasara a la jurisdicción del Cuarto Ejército del Mariscal Günther von Kluge.

Componían el Grupo de Ejércitos los Ejército Noveno, Cuarto y los Panzer Gruppe Segundo y Tercero; el Cuarto Ejército, al que se incorporaría la División, se situaba a la izquierda de la tenaza que se cernía sobre Moscú, entre el Noveno y el Panzer Gruppe de Hoth. Su contrincante debiera haber sido el General del Ejército D. G. Paulov, Jefe del distrito militar especial del Oeste que cubría el frente desde Ucrania al sur de Lituania; en España había conducido la primera brigada de tanques distinguiéndose especialmente en el contraataque republicano en la batalla de Guadalajara. Frente a él hubiera adquirido todo su sentido el carácter de devolución de visita que para los voluntarios tenía su presencia en suelo ruso, pero para cuando llegaron, Paulov ya no estaba al Frente de los Ejércitos Soviético, pues había pagado con la muerte por fusilamiento su derrota ante los alemanes ${ }^{27}$. Tampoco los divisionarios acudirían a la cita. Durante la larga marcha que tuvieron que realizar desde la frontera polaca hasta Minsk, a través de Vilna y Ozmiana, todas las deficiencias de la División fueron poniéndose de manifiesto, haciendo que los alemanes perdieran toda su confianza en ellos. Von Oertzen, se queiaba constantemente de que la marcha se realizaba en la mayor indisciplina; que no se respetaban las señales ni las distancias entre vehículos, con lo que a cada frenazo los que ocupaban la posición posterior se precipitaban sobre los que les precedían con deterioro del material; $y$ de que no se prestaba la debida atención al cuidado de las armas, de la impedimenta y del ganado. El aspecto externo de los hombres era deplorable. Marchaban sucios, desaliñados, desabrochadas las guerreras y arrastrando los capotes. Cuando llegaron a Orsha las pérdidas que habian ocasionado estos descuidos ascendían a 1205 caballos, 150 toneladas de munición y un elevado número de vehículos de todas clases. La

${ }^{27}$ Historia controvertida de la II Guerra Mundial, E. BAuER. Tomo III, págs. 140-152159 y 162. El General Paulov mandó en España la brigada de tanques que llegó los últimos días de diciembre de 1936, distinguiéndose especialmente en la batalla de Guadalajara. Ascendido a General de Ejército era Jefe del distrito militar del Oeste y su mando se extendía desde la frontera norte de Ucrania a la sur de Lituania, teniendo a sus órdenes los ejércitos $30^{\circ}$ y $100^{\circ}$. Al ser éstos derrotados fue fusilado al igual que su Jefe de EM y el General Korobkov, que mandaba el $10 .^{\circ}$ Ejército. 
gente se desprendía de todo lo que la embarazaba en su penosa marcha sin pensar en su utilidad posterior. Esta era la imagen, algo exagerada, que Oertzen presentó el 14 de septiembre a von Bock y von Kluge y por ello no es de extrañar que éste rechazara la División que de nuevo fue destinada al Noveno Ejército de Strauss. Kluge, que preguntó si lo que se le enviaba eran soldados o gitanos, se negó a unir aquellos desarrapados a sus brillantes y victoriosos Cuerpos de Ejército y la División tuvo que emprender su regreso a Orsha y girar después hacia el norte en dirección a Vitebsk, cuando Muñoz Grandes se encontró con la desagradable noticia de que tampoco el Noveno Ejército sería su destino ${ }^{28}$.

Esta fue la causa de que la ya de por sí larga marcha desde los límites de la Prusia Oriental hasta el corazón de Rusia, obligada por la destrucción de los ferrocarriles soviéticos, se viera prolongada por los cambios de dirección que impusieron los rechazos de que fue objeto la División en el sector central. Su objetivo ya no sería Moscú sino Leningrado y hacia los frentes del norte se dirigió, esta vez en ferrocarril, desde Vitebsk hasta Nowgorod, la histórica ciudad situada a orillas del río Volchov. En la noche del 10 de octubre, los españoles, cansados de la extenuante marcha de dos meses de duración que les había llevado hasta las líneas del cerco de Leningrado, empezaban a entrar en posición a lo largo de la margen derecha del río en la que cubrían un sector de 40 kilómetros que se extendía desde las márgenes septentrionales del Lago limen hasta Lubkovo, dentro de la demarcación del 16 Ejército alemán mandado por el General Ernst Busch.

\section{EN EL FRENTE DE VOLCHOV Y EN LOS CIELOS DE MOSCÚ}

En el ala norte de los Ejércitos alemanes, el Grupo de Ejércitos del Mariscal von Leeb había avanzado hasta las afueras de Leningrado, ciudad que había quedado semicercada por la doble tenaza que en su torno cerraban alemanes y finlandeses, pero cuando se disponían al asalto de la ciudad, Hitler lo impidió decidiendo que fuera sitiada y rendida por hambre, dando prioridad a las operaciones de los restantes Grupos de Ejércitos. Von Leeb insistía y finalmente se le autorizó a efectuar una maniobra de carácter secundario que tenía por objeto cerrar el cerco de

${ }^{28}$ Kleinfeld y Tambs, op. cit., págs. 91-96 y 102-103. 
Leningrado y cooperar al de Moscú. Al 16 Ejército se le ordenaba que realizara un movimiento envolvente del Lago IImen para permitir de un lado enlazar con los finlandeses en el río Svir y de otro con el Grupo de Ejércitos Central en la meseta del Valdai.

No era tarea fácil, pues a sus 15 divisiones de infantería dos motorizadas y dos panzer oponía el General Kurochkin 30 divisiones de infantería, dos de caballería y tres acorazadas y, por añadidura, la superioridad aérea local, pues la práctica totalidad de los medios aéreos y blindados alemanes se habían afectado a los Grupos de Ejércitos que desempeñaban la misión principal.

Estas decisiones, que se tomaron el 9 de octubre, la vispera de la llegada de las vanguardias de la División, fueron acompañadas de una reorganización del 16 Ejército en el que el esfuerzo principal lo realizaría el General von Both con el XXXIX Cuerpo de Ejército en el que figuraría la División Azul, aunque para las operaciones formaría parte de un grupo especial al mando de von Roques. Este grupo, inicialmente reducido a los españoles, tendría que atravesar el Volchov y presionar hacia el este atrayendo reservas que permitieran el avance de los Cuerpos de Ejército XXXIX, y I hasta Otenski, Possad y Poselok, desde donde seguirian a sus objetivos finales. Cuando la División española, la 126 y la 18 motorizada estuvieran a la otra orilla del río estas últimas también quedarian afectas al grupo von Roques.

A la espera de estos acontecimientos Muñoz Grandes estableció su cuartel General en Grigorovo, con el regimiento 262 en Novgorod, el 263 en Deveveniz y el 269 en Podbereje. El 14 de octubre toda la División estaba en línea y dispuesta para la actuación, pero para entonces los aviadores de la Escuadrilla Azul ya habían entrado en combate. El día I de octubre su escalón de vuelo llegaba al aérodromo de Moschna y se incorporaba al 27 grupo de asalto que mandaba el Mayor Weis. Era parte del VIII Cuerpo de Ejército Aéreo, el del General Manfred von Richthofen, que en España había sido jefe de la legión Condor y que conocía personalmente la capacidad y valor de los aviadores españoles que se ponían a sus órdenes. Esta fue la causa de que, con mejor suerte que sus compañeros de tierra, no fueran rechazados. El 4 de octubre la Escuadrilla lograba sus dos primeras victorias y al día siguiente, von Ritchofen, que ya había saludado a sus miembros el día I, volvía a Moschna para imponer la Cruz de Hierro 
de segunda clase al Comandante Salas, autor del doble derribo, y que fue el primer español condecorado en la Unión Soviética ${ }^{29}$.

El embajador español, molesto por la nula información que recibía de todos estos acontecimientos y cumpliendo órdenes de su Gobierno, protestó el mismo día 4 de octubre en que la Escuadrilla había entrado en fuego, del comportamiento alemán y de los continuos movimientos de la División que en ese momento todavía iba de la ceca a la meca buscando acomodo "en un lugar tranquilo"; pero el sector de la División no iba a ser tan pasivo como pensaron los que creyeron que los voluntarios españoles sólo podían ser de utilidad en un frente estático. La maniobra que se permitió a von Leeb pocos días después de que se decidiera el destino definitivo de la División la obligaría a actuar ofensivamente, aunque la misión que se la dio de constituir una cabeza de puente al otro lado del río para cubrir el flanco derecho de la penetración alemana era de carácter subsidiario.

El ataque alemán se inició el 16 de octubre con el cruce del Volchov por la 126 División en Kusino y chocó con un fuerte resistencia rusa.

Contra lo que temían los alemanes, cuando les tocó su turno, aquellos soldados de aspecto indolente, desaliñados y poco dados a las muestras externas de disciplina, se comportaron como auténticos héroes, esblecieron la cabeza de puente que se les ordenó, la ampliaron y, posteriormente, la defendieron con tesón cuando, fracasada la maniobra en sus designios estratégicos, los alemanes pasaron a la defensiva aunque no sin antes haber conquistado Tijvin, al sur del lago Ladoga.

Los alemanes, que habían considerado desdeñosamente a los españoles, quedaron maravilladós y pasaron del menosprecio al respeto. El OKW citaba por primera vez a la División el 24 de octubre: «Al defenderse de un contraataque soviético, la División española en el sector norte del Frente Oriental, ha rechazado al enemigo causándole numerosas bajas y haciendo varios centenares de prisioneros" ${ }^{30}$. Días antes había visitado la División Azul el embajador de España en Berlín, acompañado del agregado militar, Teniente Coronel Roca de Togores y del periodista Victor de la Serna que asistieron a la imposición, por el general Busch al General Muñoz Grandes y a varios de sus hombres, de la Cruz de Hierro de segunda

${ }^{29}$ A. González Martinez, Alas españolas sobre Moscú, pág. 81.

30 Kleinfeld y Tambs, op. cit., pág. 146. 
Clase y al Teniente Escobedo de la Medalla Militar, en esta ocasión en presencia de von Roques, que poco después dejaba el mando del grupo de combate que condujo en la ofensiva. La División se integraba en el XXXVIII Cuerpo de Ejército y se ponía a las órdenes de su jefe, el General von Chappuis, que informado por von Oertzen, el antiguo oficial de enlace de Muñoz Grandes, que había sido remplazado por el Capitán Collatz, no sería tan comprensivo con los españoles como lo había sido von Roques ${ }^{31}$. Su desconfianza hacia sus nuevos subordinados, de los que quiso siempre desprenderse, no se disipó ni ante las reiteradas muestras de heroísmo que constantemente le dieron. En aquellos primeros combates la División había tenido 139 muertos y 434 heridos y había sufrido por primera vez el espectro del frío. Aquel crudísimo invierno se habia adelantado y ya en octubre fueron frecuentes las intensas nevadas y las inclementes heladas que ocasionaron 79 casos graves de congelación.

Las circunstancias meteorológicas, la inmensidad de Rusia y la falta de preparación del ejército alemán para hacer frente al invierno - también los alemanes se equivocaban- concedieron a los soviéticos el respiro necesario para mover hacia vanguardia sus inagotables reservas y hacia Leningrado se dirigieron varias divisiones siberianas, acostumbradas a los inviernos rigurosos y bien equipadas contra el frío, que pronto pasaron a la contraofensiva con la idea de recuperar Tijvin. Tres ejércitos: 52,4 y 54 , se lanzaron contra el 16 alemán y a los españoles les tocó defender la cabeza de puente de Possad, lo que hicieron a costa de severas pérdidas hasta que se les ordenó replegarse a la otra orilla del río Volchov coincidiendo con la retirada del saliente del Tijvin. Habian mantenido impertérritos sus posiciones durante un mes y las abandonaban el 7 de diciembre, el día en que los Estados Unidos entraron en la guerra.

La reacción soviética había sido suficiente para dar un importante respiro a la grave situación de Leningrado pero no lo bastante como para romper las líneas alemanas que se mantuvieron firmes aunque sufriendo constantes embestidas rusas. Se había producido un profundo cambio en la situación militar pero todavía no una inversión.

Este hecho, innegable, tuvo sus inevitables reflejos en la política interior española, donde Serrano Súñer tropezaba con una oposición cada vez más abierta en los círculos militares. Los de tendencia anglófila cons-

${ }^{31}$ KLEINFELD y TAMBS, op. cit., págs, 183-205, y 207-208. Los autores detallan las tensas relaciones entre Muñoz Grandes y su inmediato superior von Chappuis. 
piraban contra el régimen en contacto más o menos velado con la Embajada inglesa, siendo sus hombres más significativos el General Aranda y el Coronel Beigbeder, anterior ministro de Asuntos Exteriores. Los monárquicos, entre los que había generales tan destacados como Kindelán y civiles como el Duque del Infantado, Sáinz Rodríguez, García Valdecasas y Areilza, trabajaban a favor de la restauración y no faltaban falangistas, como Yagüe, que querían volver a las esencias originarias de este movimiento que creían adulterado. La falta de coordinación de todas estas conjuras, que no tenían en común más que el deseo de eliminar a Serrano Súñer, limitaban su eficacia, pero la posición del todopoderoso ministro iba debilitándose al ritmo del decaimiento alemán.

Simultáneamente estaban en curso complicadas combinaciones de política exterior. A fines de noviembre viajó a Alemania y se acercó a Rusia, donde asistió a la entrega por parte de von Chappuis de la Cruz de Guerra de la primera Clase a Muñoz Grandes, el General Moscardó, que se cruzó con el Almirante Canaris que también en misión oficial visitaba España, y con Serrano Súñer que acudió a la reunión que en Berlín celebraron las naciones firmantes del Pacto Anticomintern, ocasión en la que se entrevistó con Hitler y Ribbentrop que no quedaron satisfechos de la postura española, amistosa, pero no servil ${ }^{32}$.

Entretando los rusos continuaban presionando en el frente oriental y cuando el año terminaba, consiguieron cercar casi totalmente a dos cuerpos de Ejércitos alemanes en la orilla sur del algo IImen. Para socorrerlos acudió la compañía especial de esquiadores de la División, que inició su marcha sobre el lago helado el 10 de enero de 1942, estableció contacto con el enemigo al día siguiente y mantuvo una lucha constante hasta el día 25 , en que una vez cumplida su misión de enlace regresó a su base de partida. La compañía, que al salir contaba son 206 hombres, había quedado reducida a sólo 12. Su heroísmo fue premiado con una citación colectiva, dos Medallas Militares individuales y gran número de Cruces de Hierro.

${ }^{32}$ Muñoz Grandes recibió la Cruz de Hierro de $1 .^{\text {a }}$ Clase el 6 de enero de 1942 y la entrevista de Serrano Súñer con Hitler se celebró el martes 18 de noviembre de 1941. Según el ex-ministro español, Hitler le conminó para que "de acuerdo con lo convenido en Hendaya», fijara la fecha de entrada de España en la Guerra, a lo que contestó "que lo convenido en Hendaya no había sido que España entrara en la guerra cuando ellos - los alemanes- decidieran, sino cuando nosotros estuviéramos en condiciones de hacerlo". Entre el silencio y la propaganda, la Historia como fue, pág. 306. 
Siguió un compás de espera, aunque no la tranquilidad. Los rusos, en su contraofensiva invernal, habian conseguido durante el mes de enero establecer una amplia cabeza de puente a la orilla derecha del Volchov pero quedaron en mala situación y las tropas del segundo Ejército soviético que las ocupaban serian aniquiladas en la primavera con la contribución de los españoles. En la operación caería prisionero su propio jefe, el General Vlasov, que se uniría a los alemanes y terminaría su vida ahorcado por traidor al finalizar la guerra.

Del lado alemán también se habían producido acontecimientos significativos. La entrada en guerra de los Estados Unidos y la pérdida progresiva de la capacidad ofensiva alemana presagiaban un fin bastante distinto al que se supuso en los medios oficiales españoles y todo parecía indicar que comenzaba la lenta agonía del III Reich, aunque sus tropas recuperaran la iniciativa durante la primavera y el verano de 1942, tanto en Rusia como en el Mediterráneo. En el Grupo de Ejércitos Norte, von Leeb había sido sustituido mediado el mes de enero por von Küchler, jefe del 18 Ejército, relevado a su vez por Lindemann, del que desde el 23 de febrero dependeria el XXXVIII Cuerpo de Ejército, al que pertenecía la División española y cuyo jefe sería sustituido el 29 de marzo por el General Haenicke, con satisfacción de Muñoz Grandes ${ }^{33}$.

Franco, ante esa situación, tomó postura y el 14 de febrero, después de una reunión con Oliveira Salazar, afirmó que si los soldados soviéticos lograban abrirse camino hacia Berlín, no una división, si no un millón de españoles tratarían de cerrarles el paso, pero, paradógicamente, comenzaba por esas mismas fechas a pensar en la retirada de los soldados españoles para los que pedía el inmediato descanso y merecido relevo ${ }^{34}$.

33 KLeINFELD y TAMBS, op. cit., págs. 241-242 y 266.

${ }^{34}$ La entrevista entre Franco y Oliveira Salazar se celebró en Sevilla el 12 de febrero de 1942 y fue en esa ciudad donde Franco pronunció el discurso en el que después de decir que Alemania suponía una muralla de contención a las hordas rojas, dijo textualmente: «En estos momentos de lucha entre los pueblos del mundo vemos cómo se pretende destruir esa muralla y cómo se ofrece a Europa como posible presa al comunismo. No tememos su realización; tenemos la absoluta seguridad de que no será así; pero si hubiera un momento de peligro, si el camino de Berlín fuese abierto, no sería una división de voluntarios españoles lo que allí fuese, sino que sería un millón de españoles los que se ofrecerian». "Palabras del Caudillo». Madrid 1943, pág. 204, citado por L. SUÁREZ FERNÁNDEZ en Franco, la historia y sus documentos. Ed. Urbión, 1986. Tomo VI, pág. 40. 


\section{RELEVO Y CAMBIO DE FRENTE}

El General Asensio, Jefe del Estado Mayor Central español, viajó en marzo a Berín para tratar de estas importantes cuestiones, mientras en España se ordenaba al General Esteban Infantes, Jefe de Estado Mayor de la IV Región Militar, que se presentase en Madrid para encargarse de estudiar y preparar el relevo de la División Azul. A últimos de abril empezaron a llegar a Alemania las primeras expediciones y en mayo comenzaban a entrar en línea en el Volchov, a tiempo para participar en la limpieza de la "bolsa". La recluta no resultó tan fácil como el año anterior y los nuevos voluntarios diferían bastante de los primeros. El entusiasmo había disminuido y "se iba agotando la cantera de los mejor dispuestos".

Antes de que comenzara el verano se había sustituido aproximadamente un tercio de la División y entraba en las intenciones de Franco que entre los relevados figurara el propio General Muñoz Grandes, pero Hitler se opuso terminantemente, retuvo en Berlin a Esteban Infantes y logró que el prestigioso General, en quien pensaba para más altas empresas, siguiera en su puesto.

La División pasó a descansar y reorganizarse en agosto y dejaba a orillas del Voljov 1.400 de sus hombres que en ellas reposarían eternamente. Sólo durantè el invierno sus pérdidas se elevaron a 1.119 muertos, 1.240 congelados y 2.398 heridos ${ }^{35}$.

Su nuevo destino serían los arrabales de Leningrado. Se reunió en los alrededores de Vyriza, entre Grigorovo y Gaschina, y allí permaneció varias semanas haciendo instrucción intensiva y completando su personal y material. Seguía afecta al 18 Ejército y se integraba en el XXIV Cuerpo de Ejército, que mandaba el General Hansen. Se hablaba insistentemente de que participaría en el asalto definitivo a la antigua capital de los Zares.

Mientras tanto se habían producido en España importantes acontecimientos que tendrían repercusión en las lejanas estepas rusas. Unos incidentes acaecidos en Bilbao el 15 de agosto y que enfrentaron a me-

${ }^{35}$ Según el General E. INFANTES, La División Azul. Ed. AHR, Barcelona 1956, pág. 300, las bajas de la División en 1941 fueron 718 muertos, 1.612 heridos y 86 desaparecidos; y las de 1942, 1252 muertos, 2.777 heridos y tres desaparecidos. Las cifras que citamos en el texto son los datos de la «División» hasta el 21 de marzo de 1942. 
dios militares y falangistas fueron aprovechados por Franco para efectuar un profundo cambio en el Gobierno. El General Varela y Serrano Súñer eran destituidos y reemplazados, el primero por el General Asensio y el segundo por el General Gómez Jordana, -hombre moderado e inclinado a los aliados, que ya había dirigido la diplomacia española - en Asuntos Exteriores y por el propio Franco en la jefatura de la Junta Política ${ }^{36}$.

Cuando la División Azul se situó en su nuevo frente lo hizo en un sector cruzado por los ríos Slavianka e Ishora, afluentes del Neva, y sus posiciones cubrian las localidades de Puschkin - la antigua residencia veraniega de los Zares Zsarkoje-Elo- y Krasnybor. Los rumores se confirmaban y llegaba el Mariscal Manstein, el famoso conquistador de Sebastapol, para repetir suerte ante Leningrado, pero el 27 de agosto Meretskov se adelanta y desencadena una ofensiva que sorprende a los alemanes. Aunque no tiene éxito, si retrasa los preparativos germanos que durante semanas se ven forzados a una defensiva durante la que los españoles tuvieron que repeler varios ataques, distinguiéndose especialmente el Capitán Portolés que el 12 de octubre aniquiló a los asaltantes de la posición que defendía.

Manstein todavía creía que se daban las condiciones necesarias para llevar a cabo su misión pero las circunstancias habían variado notablemente. El General Warlimont, eminencia gris del Estado Mayor alemán, escribía el 31 de octubre: "Clara es la conclusión: El Ejército alemán y sus aliados han hecho cuanto han podido y ya no pueden hacer más" ${ }^{37}$. Cuatro días más tarde Rommel iniciaba su retirada en El Alamein; ocho después, los aliados occidentales desembarcaban en Marruecos y Argelia y sólo treinta y dos tardarían los soviéticos en sitiar a von Paulus con su VI Ejército en Estalingrado. Para España fue un momento delicado. La presión alemana, que al ocupar la totalidad de Francia amplió notablemente su frontera con nosotros, se acentuó, volviendo a hablarse insistentemente de una invasión de la Península que no se ajustaría al plan Félix, sino a uno nuevo que se denominaría Gisela. La aliada se hizo igualmente insistente y conminatoria.

${ }^{36}$ Franco demoró la crisis hasta el 3 de septiembre, fecha en que constituyó su quinto Gobierno, en él pasó a ocupar al Minisierio del Ejército el General Asensio Cabanillas; en Gobernación Blas Pérez González sustituyó a Valentín Galarza y Serrano Súñer cedió el Ministerio de Asuntos Exteriores al Conde de Jordana y al propio Franco la Jefatura de la Junta Política.

${ }^{37}$ Warlimont, con el empleo de Teniente Coronel, y usando el seudónimo de Teniente Coronel Walter, fue Jefe de las fuerzas alemanas en España hasta la llegada de la "Legión Condor". 
También pensaron en ocupar las islas Canarias e incluso la España continental, aunque haciéndola depender de la conducta que observaran los alemanes, y exigieron de Franco la interrupción del comercio con las potencias del Eje, la prohibición de la propaganda germano-italiana en España y la retirada de la División y la Escuadrilla. Todo ello les sería concedido aunque a lo largo de los meses.

La ofensiva de Manstein se canceló, Muñoz Grandes cesó en el mando de la División el 12 de diciembre y después de despedirse de Hitler, que le premió con las Hojas de Roble sobre las insignias de Caballero de la Cruz de Hierro, regresó a Madrid donde le esperaba el ascenso a Teniente General. Parece ser que Hitler aceptó su relevo en la idea de que en España dirigiría el sector de opinión pro-alemán, incluso contra Franco, pero si ésta fue su intención eligió mal la persona. Su lealtad era mayor que la de muchos de sus compañeros que, infructuosamente, trataban o bien de uncir nuestra patria al carro alemán o bién, por el contrario, de buscar una salida más concorde con los deseos de quienes ya se perfilaban como seguros vencedores ${ }^{38}$.

En esta situación, tan poco propicia para mantener elevada la moral de los combatientes, los divisionarios se tuvieron que enfrentar con la más dura prueba que sufrieron en Rusia. La gran ofensiva soviética contra sus líneas de Krasnybor iniciada en la madrugada del 10 de febrero de 1943 cuando más de 800 cañones rusos concentraron sus fuegos sobre las líneas defendidas por los españoles. Éstos, como siempre, resistieron con una tenacidad increíble y aunque se vieron obligados a retroceder, cediendo algunas de sus posiciones, mantuvieron el frente a costa de notables sacrificios. En la acción cayeron prisioneros del orden de los 300 divisionarios y en ella se distinguieron de una manera especial los hombres del batallón de reserva y la compañía divisionaria de zapadores que al mando del Capitán Aramburu, llevó a cabo una notable defensa y una increíble retirada al precio de ver reducidos sus efectivos de 172 hombres a únicamente 32 , y algunos de ellos heridos.

El año 1943 fue un año claramente decisivo y durante él la iniciativa pasó íntegramente a manos aliadas. En un último intento por restablecer,

${ }^{38}$ Posiblemente, Muñoz Grandes, después de su entrevista el 13 de diciembre con Hitler tuviera alguna veleidad política, pero, en cualquier caso, fue corta y las esperanzas que en él depositaron los alemanes quedaron defraudadas. Por decreto del 12 de diciembre ascendía a Teniente General por méridos de guerra y el 2 de marzo de 1943 era nombrado Jefe de la Casa Militar del Generalisimo. 
o, al menos, aliviar, la difícil situación estratégica alemana, el mariscal Kesselring, jefe de las fuerzas alemanas en el sur de Europa, y el almirante Doenitz, Comandante de la marina, vuelven a aconsejar la invasión de España para proteger el flanco de sus fuerzas y amenazar el de sus contrarios. Era una tentativa que entraba dentro de las posibilidades alemanas, como se demostró con la posterior ocupación y defensa de Italia, pero Hitler la rechazó diciendo: "Ocupar España sin consentimiento de los españoles es algo que ni siquiera merece discutirse, pués son los últimos latinos valientes y formarían guerrillas en nuestra retaguardia misma ${ }^{39}$ ". En los meses siguientes la guerra aceleraría su cambio de ritmo. El 10 de junio los aliados invadían Sicilia, el 24 de ese mismo mes Mussolini era depuesto por el Gran Consejo fascista y el 8 de septiembre, los ingleses desembarcaban en Calabria. Cinco días antes se firmaba en Siracusa un armisticio secreto entre Italia y los aliados y al mes siguiente, Badoglio, nuevo Jefe del Gobierno italiano y generalísimo de sus fuerzas, invierte las alianzas y declara la guerra a Alemania.

\section{VUELTA A LA NEUTRALIDAD Y RETIRADA A LA DIVISIÓN. LA LEGIÓN AZUL}

Franco que había dirigido un llamamiento a la Paz el día 9 de mayo, reafirmaba su estricta postura de neutralidad en el conflicto, lo que no resultaba incoherente pues si su declaración de "no beligerancia» se apoyó en su simpatía por Italia, su vuelta a la neutralidad resultaba concordante con el cambio de actitud de esta potencia. El día 25 de septiembre decide la repatriación de la División Azul, medida a la que los alemanes opusieron débiles reparos que se salvaron con el mantenimiento de la que se llamó "Legión Azul» ${ }^{40}$.

El relevo se inició el día 9 de octubre y el día 17 de noviembre el general Esteban-Infantes firmaba la órden general por la que se disolvía

39 Proctor, op. cit, pág. 240.

${ }^{40}$ El acuerdo de retirar la "Divisón» se tomó en Consejo de Ministros el 25 de septiembre y fue comunicado al Gobierno aleman por Vidal y Saura, embajador de España en Berlín, el 1 de octubre. Goebbels expresó su disgusto el día 8 de octubre en un discurso pronunciado en el Reichstag, y los aliados, a cuya presión se debía la medida, tampoco quedaron satisfechos por que no fue completa. 
la brillante unidad que de forma tan destacada había combatido durante dos años en un suelo lejano y en un medio enormemente hostil.

La legión que la sutituyó quedó al mando del coronel García Navarro y la formaban tres banderas de 500 hombres con una pequeña reserva que situaba el total próximo a los 2.000 combatientes. La nueva unidad salió para el frente el día 15 de diciembre y se la situó en el sector de Kostov, próximo al que ocupó inicialmente la División. Allí habrian de sufrir la dura ofensiva de invierno del ejército soviético que en enero de 1944 obligó al Grupo de Ejércitos alemanes a retirarse definitivamente de las líneas de asedio a Leningrado. García Navarro conservó hasta entonces sus puestos con la misma tenacidad con que anteriormente lo habian hecho los divisionarios. Las posiciones ocupadas por los españoles nunca fueron fácil presa de quienes las atacaron.

El mantenimiento de este remanente de voluntarios en Rusia indignó a los aliados que presentaron sus quejas al Gobierno español. Jordana, que nunca fue partidario de la constitución de la Legión, no se opuso a su retirada y los alemanes tampoco se resistieron demasiado a una medida que poco podía influir en la guerra.

A fines de febrero la legión regresaba a España y la medida comprendía también a la Escuadrilla Azul que hasta entonces había seguido combatiendo en los cielos de la Rusia Central. Cuatro veces se había sustituido su personal y los aviadores dejaban el recuerdo de hazañas que resistían perfectamente la comparación con las realizadas por sus compañeros de tierra. 163 aviones derribados con la pérdida definitiva de 25 pilotos y un especialista, da idea de la gesta realizada por estos hombres, entre los que destacaron por el número de sus derribos el Comandante Cuadra, los Capitanes Hevia y Gavilán y el teniente Sánchez Arjona.

Pero no terminaría así la odisea de los españoles en tierras Rusas, pues un cierto número de éstos, aventureros, idealistas y fanáticos, expresaron su voluntad de continuar en una lucha sin horizontes, y, clandestinamente, se incorporaron a las milicias de las SS dentro de las que llegaron a constituir tres compañías. Una de ellas quedó afecta a la División Valona de voluntarios belgas rexistas, otra se unió a una brigada croata y la tercera a un batallón alemán. A primeros de 1945 los voluntarios españoles se integraron en las compañías 101 y 102 de las SS que se afectaron a la 357 División alemana de Infantería y parece ser que actuaron en Eslovaquia al noroeste de Bratislava. 
El final de estas unidades se produjo en el mismo Berlín ciudad en la que sucumbieron defendiendo el edificio de la cancillería en unión de una heterogénea fuerza que incluía voluntarios belgas, holandeses, daneses, suecos, estonianos, letones, franceses y suizos. Esto hombres, los españoles, fuera de la disciplina del ejército español y amenazados con la privación de la nacionalidad, combatieron hasta el final y lo hicieron con heroísmo digno de mejor causa. Muy pocos escaparon a la muerte y de ellos 22 fueron hechos prisioneros, uniéndose en los campos de concentración a los varios cientos de divisionarios que en ellos sufrieron prolongado cautivario.

Para éstos el epílogo sería largo y en la mayoría de los casos definitivo. Ya en marzo de 1954, casi trece años después de que se iniciara la aventura, España conseguía, a través de la Cruz Roja Internacional, la repatriación de los supervivientes. El día 26 de marzo, embarcaban 291 en Odesa a bordo del barco griego Semiramís que atracó en Barcelona el día 2 de abril donde se recibió a los liberados en un ambiente multitudinario hondamente emotivo. Millares y millares de españoles dieron su emocionada bienvenida a aquellos españoles, compatriotas suyos, que habían soportado, después de los horrores de la guerra, entre 10 y 12 años de cautiverio. Su sacrificio y el de los 3.934 muertos, 8.466 heridos y 326 desaparecidos, oficialmente contados, no había sido estéril. Por Rusia habían pasado más de 47.000 españoles de los que muy cerca del 10 por 100 quedaron para siempre en la estepa rusa. Su epopeya, fracasada en lo militar, había sin embargo contribuido eficazmente a mantener a España alejada de la guerra, saldando, con su heroísmo y de forma amplia, la deuda de sangre que se habia contraído con Alemania y una parte muy importante de la deuda ecónomica. Según Angel Viñas, los pagos en España por gastos de la División Azul redujeron las obligaciones contraídas durante la Guerra Civil, en casi el 38 por 100 de su importe total.

El comportamiento de los voluntarios fue suficiente causa para que tanto los alemanes como sus enemigos lo pensaran dos veces antes de decidirse a violar nuestra neutralidad, y en tanto que la disminución de la deuda supuso un notable alivio en la penosa situación que atravesaba nuestro pueblo. Una y otra circunstancia son suficientes para poder afirmar que la División Azul resultó a la postre beneficiosa para España y que todos los españoles contrajimos una deuda de gratitud con aquellos hombres que románticamente acudieron a una lucha en la que, al parecer, nada les iba ni venía. 